\title{
Results of surgical treatment of ventricular septal defects with pulmonary hypertension
}

\author{
STANLEY JOHN, ROY KORULA, PS JAIRAJ, S MURALIDHARAN, EDWIN \\ RAVIKUMAR, C BABUTHAMAN, I SATHYAMOORTHY, S KRISHNASWAMY, \\ GEORGE CHERIAN, IP SUKUMAR
}

From the Departments of Cardiothoracic Surgery and Cardiology, Christian Medical College and Hospital, Vellore 632004 , India

ABSTRACT Two hundred and twenty-five consecutive patients with interventricular septal defect and associated pulmonary hypertension have undergone corrective surgery at the Christian Medical College Hospital. The mean preoperative systolic pulmonary artery pressure was 70.5 (range 31-136) $\mathrm{mm} \mathrm{Hg}$ and the calculated pulmonary vascular resistance ranged from 300 to $1680 \mathrm{dyn} / \mathrm{s}$ $\mathrm{cm}^{-5}$. A paracoronary right ventriculotomy was the approach of choice. Profound hypothermia and circulatory arrest were not used, even in 12 patients weighing under $10 \mathrm{~kg}$. Among the older children and young adolescents there were 27 who had a calculated pulmonary vascular resistance of over $800 \mathrm{dyn} / \mathrm{s} \mathrm{cm}^{-5}$ and their mortality was $22 \%$, which is good when compared with that of other series. It is evident that both the early and the late death rate after surgery increase with the age of the patient, especially in those with associated pulmonary hypertension. In 69 patients studied after repair recatheterisation showed no residual defect by oximetry. The fall in the pulmonary artery pressures after surgery has been striking in most patients. The late death rate was $2.5 \%$. The surviving patients are leading normal, active lives.

In 1879 Roger described the clinical signs of ventricular septal defect and indicated the underlying pathology. ${ }^{1}$ Maude Abbott ${ }^{2}$ gave credit to Dalrymple as being the first to describe Eisenmenger's complex in 1874 , by reporting a postmortem study on a 45-year-old woman who had had cyanosis for several years before her death. Lillehei et al in 1954 was the first to use cardiopulmonary bypass with controlled cross-circulation to close the defect. ${ }^{3}$ Several studies since have documented the benefits that accrue from closure of a ventricular septal defect, even in those with pulmonary hypertension. ${ }^{4-7}$ From 1966 to April 1982, of 293 patients undergoing surgical correction of ventricular septal defects in our department of cardiothoracic surgery, 225 had complicating pulmonary hypertension. The results in this group form the basis of our report.

Address for reprint requests: Professor Stanley John, Department of Cardiothoracic Surgery, Christian Medical College Hospital,
Vellore 632004 , India.

Accepted 14 December 1982

\section{Patients and methods}

The youngest of the 225 patients was aged 6 months and the oldest 33 years (mean $9 \cdot 1$ years)-see figure 1 and table 1 for the age distribution.

All patients had pulmonary hypertension. The mean preoperative systolic pulmonary artery pressure was 70.5 (range 31-136) $\mathrm{mm} \mathrm{Hg}$. The calculated pulmonary vascular resistance ranged from 300 to $1680 \mathrm{dyn} / \mathrm{s} \mathrm{cm}^{-5}$ (3.75-21 units (Wood)). In 27 patients the pressures were equal in the right and left ventricles with a pulmonary vascular resistance higher than $800 \mathrm{dyn} / \mathrm{s} \mathrm{cm}^{-5}$. During the last two years the response to inhalation of $100 \%$ oxygen was determined in 30 patients in whom the pulmonary artery systolic pressure was $50-100 \%$ of the systemic pressure. The fall in pulmonary artery pressure and pulmonary vascular resistance is shown in table 2 .

Most of the ventricular septal defects were infracristal, in the membranous portion of the septum (type II) ${ }^{8}$ but they were supracristal (type I) in 33 cases and in the muscular septum in five. In most cases the defect was large, with a mean diameter of 


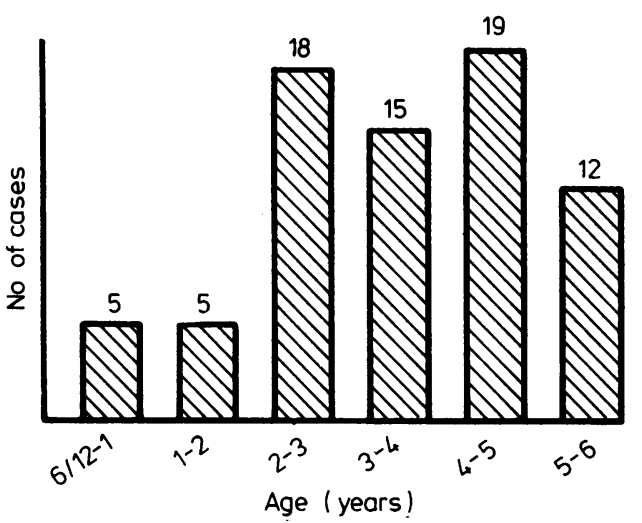

Fig 1 Age distribution of the younger patients.

$2.25 \mathrm{~cm}$. The commonest associated anomalies were patent ductus arteriosus (in 21 patients) and mild aortic incompetence (in 16).

In all cases closure of the ventricular septal defect was performed with cardiopulmonary bypass and moderate total body hypothermia. Even in 12 patients weighing under $10 \mathrm{~kg}$ we used conventional bypass rather than profound hypothermia with circulatory arrest. The ventricular septal defect was exposed in all patients through a paracoronary right ventriculotomy that avoided major coronary artery branches. In all but 21 cases the defect was closed with a Dacron patch that was anchored in place with buttressed interrupted mattress sutures. In the posteroinferior portion of type II and type III defects the

Table 1 Age distribution in the 225 patients with pulmonary hypertension undergoing surgical correction of ventricular septal defects

\begin{tabular}{cl}
\hline Age $(y)$ & No of patients \\
\hline $6 / 12-5$ & 74 \\
$6-10$ & 66 \\
$11-20$ & 70 \\
$21-35$ & 15 \\
\hline
\end{tabular}

Table 3 Causes of early postoperative death

\begin{tabular}{|c|c|}
\hline & No of cases \\
\hline Low cardiac output & 8 \\
\hline Unsatisfactory perfusion & 10 \\
\hline Disseminated intravascular coagulation & 3 \\
\hline Septicaemia & 3 \\
\hline Ventricular arrhythmia & 4 \\
\hline Fungal encephalitis & 1 \\
\hline Aspiration & 1 \\
\hline Cerebral hypoxia & 3 \\
\hline Convulsions & 5 \\
\hline Total & 38 \\
\hline
\end{tabular}

sutures were placed caudad and to the right of the edge of the defect to avoid injury to the conduction system.

In seven patients early in the series a patent duc tus was ligated intrapericardially before cardiopulmonary bypass was established. More recently, in 18 patients, we have adopted the transpulmonar. approach to obliterate the ductus, as we have already reported. ${ }^{9}$

Postoperative care included careful maintenance of blood volume and replacement of blood losse from the chest. Many of the patients, includin infants, required inotropic support. Ventilation was assisted overnight in all cases and tracheostomp with prolonged ventilatory assistance, was carried out in those with severe pulmonary vascular disease?

\section{Results}

Of the 225 patients, 38 died within 30 days of opera tion, giving a hospital death rate of $16.9 \%$ for the group. During the last six years, however, the deat rate has been only $10 \%$. The causes of death are shown in table 3. Technical imperfections in the car 8 diopulmonary bypass were responsible for $1 \mathrm{~B}$ deaths. Low cardiac output with congestive failure was another frequent cause. The mortality in relation to age and pulmonary vascular resistance shown in table 4. Of those with non-fatal complica

Table 2 Preoperative response to inhalation of $100 \%$ oxygen

\begin{tabular}{|c|c|c|c|c|c|c|}
\hline \multirow[t]{2}{*}{$\begin{array}{l}\text { Age group } \\
(y)\end{array}$} & \multirow[t]{2}{*}{$\begin{array}{l}\text { No of } \\
\text { cases }\end{array}$} & \multicolumn{2}{|c|}{$\begin{array}{l}\text { Systolic pulmonary artery pressure range } \\
\text { (and mean) ( } \mathrm{mm} \mathrm{Hg})\end{array}$} & \multicolumn{3}{|c|}{$\begin{array}{l}\text { Pulmonary vascular resistance range (and mean } \\
\text { (units (Wood)) }\end{array}$} \\
\hline & & Before oxygen & After oxygen & Before oxygen & After oxygen & \\
\hline $6 / 12-2$ & 4 & 68-85 & 66-75 & $\begin{array}{l}7-19 \\
(13 \cdot 1)\end{array}$ & $\begin{array}{l}2 \cdot 6-17 \cdot 5 \\
(7 \cdot 2)\end{array}$ & \\
\hline $3-6$ & 12 & $\begin{array}{l}65-101 \\
(81 \cdot 9)\end{array}$ & $\begin{array}{l}60-87 \\
(71.7)\end{array}$ & $\begin{array}{l}4 \cdot 1-21 \\
(12 \cdot 1)\end{array}$ & $\begin{array}{l}0 \cdot 6-5 \cdot 1 \\
(2 \cdot 9)\end{array}$ & \\
\hline $7-10$ & 4 & $\begin{array}{l}78-104 \\
(91 \cdot 2)\end{array}$ & $\begin{array}{l}53-102 \\
(83.7)\end{array}$ & $\begin{array}{l}5.4-16 \cdot 1 \\
(13.6)\end{array}$ & $\begin{array}{l}0.7-4.8 \\
(3.0)\end{array}$ & \\
\hline $11-20$ & 8 & $\begin{array}{l}70-118 \\
(95.4)\end{array}$ & $\begin{array}{l}60-101 \\
(86 \cdot 1)\end{array}$ & $\begin{array}{l}3 \cdot 3-16 \cdot 8 \\
(10 \cdot 2)\end{array}$ & $\begin{array}{l}0.4-6 \cdot 3 \\
(3 \cdot 9)\end{array}$ & \\
\hline $21-35$ & 2 & $\begin{array}{l}108-130 \\
(119)\end{array}$ & $\begin{array}{l}105-120 \\
(112 \cdot 5)\end{array}$ & $\begin{array}{l}8-18 \cdot 1 \\
(13 \cdot 0)\end{array}$ & $\begin{array}{l}2 \cdot 10 \\
(6 \cdot 0)\end{array}$ & \\
\hline
\end{tabular}


Table 4 Hospital mortality among the 225 patients by age and pulmonary vascular resistance (PVR)

\begin{tabular}{|c|c|c|c|c|c|c|c|c|c|}
\hline \multirow{4}{*}{$\begin{array}{l}\text { PVR } \\
\text { (units (Wood)) }\end{array}$} & \multicolumn{8}{|c|}{ Age (years) } & \multirow{4}{*}{$\begin{array}{l}\text { Mortality } \\
\text { (\%) }\end{array}$} \\
\hline & \multirow{2}{*}{\multicolumn{2}{|c|}{$\frac{6 / 12-5}{\text { No of }}$}} & \multirow{2}{*}{\multicolumn{2}{|c|}{$\frac{6-10}{\text { No of }}$}} & \multirow{2}{*}{\multicolumn{2}{|c|}{$\frac{11-20}{\text { No of }}$}} & \multirow{2}{*}{\multicolumn{2}{|c|}{$\frac{21-35}{\text { No of }}$}} & \\
\hline & & & & & & & & & \\
\hline & cases & deaths & cases & deaths & cases & deaths & cases & deaths & \\
\hline $\begin{array}{c}3.75-4 \\
4.1-7.9 \\
8.0-9.9 \\
\geqslant 10.0\end{array}$ & $\begin{array}{r}33 \\
25 \\
7 \\
9\end{array}$ & $\begin{array}{l}7 \\
3 \\
4 \\
4\end{array}$ & $\begin{array}{r}25 \\
26 \\
7 \\
8\end{array}$ & $\begin{array}{l}1 \\
2 \\
2 \\
2\end{array}$ & $\begin{array}{r}30 \\
24 \\
8 \\
8\end{array}$ & $\begin{array}{l}5 \\
2 \\
2 \\
0\end{array}$ & $\begin{array}{l}7 \\
5 \\
1 \\
2\end{array}$ & $\begin{array}{l}2 \\
1 \\
1 \\
0\end{array}$ & $\begin{array}{l}15 \cdot 8 \\
10 \cdot 0 \\
39.1 \\
22 \cdot 2\end{array}$ \\
\hline
\end{tabular}

Table 5 Preoperative systolic pulmonary artery $(P A)$ pressure and response to oxygen and postoperative pressure for six patients

\begin{tabular}{|c|c|c|c|c|}
\hline \multirow[t]{2}{*}{ Patient No } & \multirow[t]{2}{*}{ Age (y) } & \multicolumn{2}{|c|}{ Preoperative PA pressure $(\mathrm{mm} \mathrm{Hg}$ ) } & \multirow{2}{*}{$\begin{array}{l}\text { Postoperative PA pressure } \\
(\mathrm{mm} \mathrm{Hg})\end{array}$} \\
\hline & & Before oxygen & After oxygen & \\
\hline $\begin{array}{l}1 \\
2 \\
3 \\
4 \\
5 \\
6\end{array}$ & $\begin{array}{r}5 \\
6 \\
9 \\
17 \\
19 \\
26\end{array}$ & $\begin{array}{r}94 \\
101 \\
104 \\
108 \\
112 \\
130\end{array}$ & $\begin{array}{r}85 \\
87 \\
102 \\
107 \\
111 \\
120\end{array}$ & $\begin{array}{l}49 \\
44 \\
47 \\
42 \\
61 \\
54\end{array}$ \\
\hline
\end{tabular}

tions, only two had complete postoperative heart block.

There were six late deaths: four were due to infective endocarditis, one to complete heart block four months after surgery, and the other to a drowning accident three years after repair. Recatheterisation in this patient earlier had shown normal pulmonary artery pressures. The remaining 181 patients have been followed up for one to 16 years (mean 5.8 years). They are symptom free and leading normal, active lives (fig 2 ).

Haemodynamic studies were carried out in 69 patients who agreed to recatheterisation one to

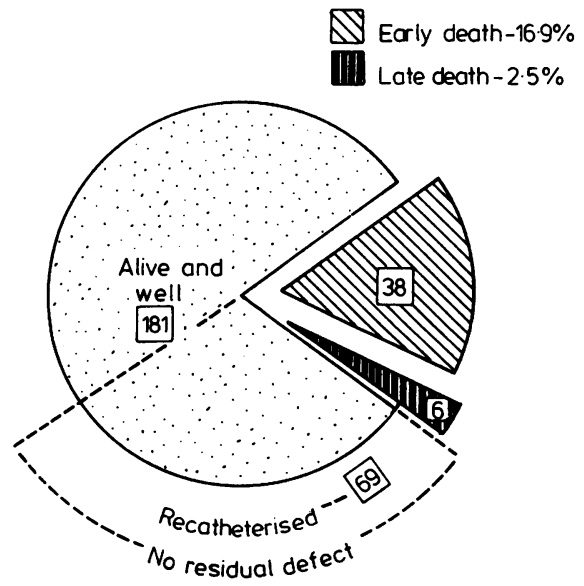

Fig 2 Early and late results after corrective repair. three years after repair. None showed any residual defect by oximetry; one patient had a very small residual jet shown on cineangiocardiography. Systolic pulmonary artery pressures are shown in figure 3 ; in three subjects the pressures had fallen by 40-60 $\mathrm{mm} \mathrm{Hg}$ from preoperative levels, but remained above $60 \mathrm{~mm} \mathrm{Hg}$. In six of the 69 patients

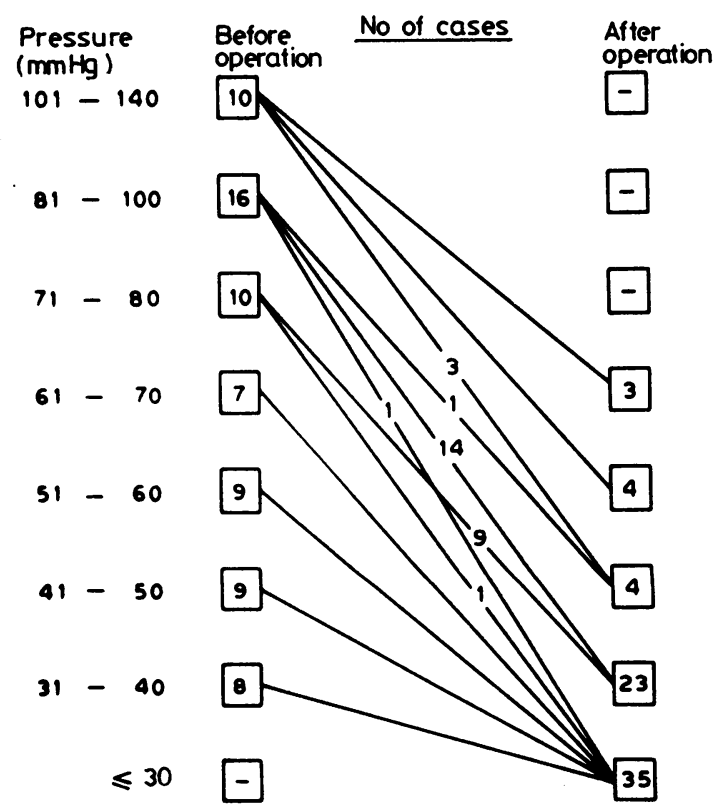

Fig 3 Systolic pulmonary artery pressures in 69 patients before and after closure of the defect. 


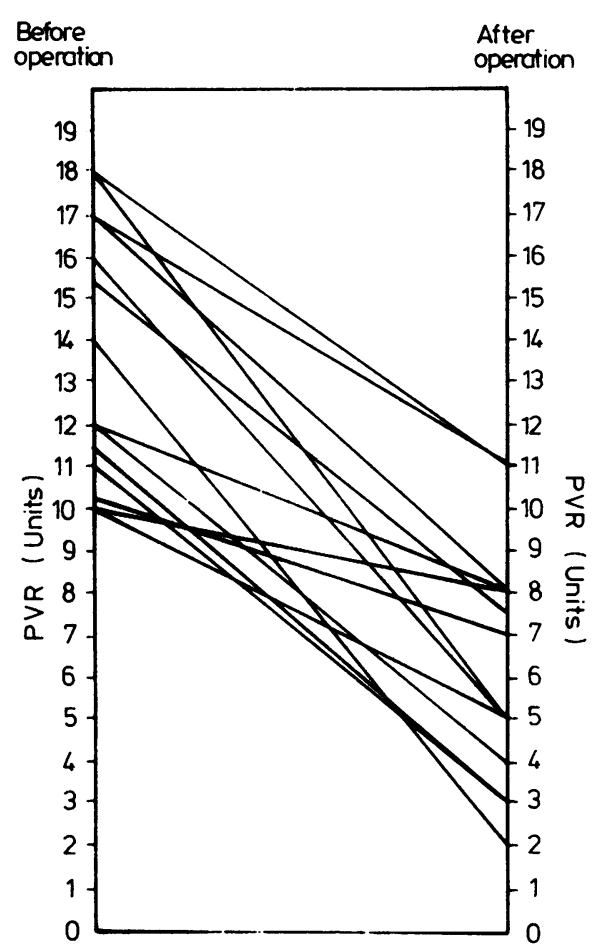

Fig 4 Results of operation in 14 patients with a pulmonary vascular resistance greater than 10 units (Wood) before operation

who were recatheterised the preoperative response to $100 \%$ oxygen inhalation had been-determined, and table 5 shows how far below these levels the systolic pulmonary artery pressure fell after operation. Pulmonary vascular resistance was calculated before and after correction in 14 patients with a preoperative level above $800 \mathrm{dyn} / \mathrm{s} \mathrm{cm}^{-5}$. In these patients there was a considerable fall in all except four patients and no case of a rise in pressure (fig 4). All these patients are symptom free.

\section{Discussion}

In this series of patients ranging in age from 6 months to 33 years an appreciable number were in the second decade of life. The possibility that many of these patients would have developed Eisenmenger's complex if surgery had not been performed is fairly strong, perhaps $15-20 \% .^{10}$ Pulmonary vascular disease may regress completely up to the age of 2 years if the causal defects are corrected, but if surgery is deferred until after childhood this is less likely. 41112

It is noteworthy that in 27 patients the large ventricular septal defects were associated with equal systolic pressures in the two ventricles, while in $13 \overrightarrow{\overrightarrow{\hat{\sigma}_{3}}}$ patients the calculated pulmonary vascular resiso tance was over $320 \mathrm{dyn} / \mathrm{s} \mathrm{cm}^{-5}$ (4 units (Wood) Recatheterisation in 69 patients after corrective repair has shown a drop in pressure in all. In thre⿷ cases, however, the pressures were still appreciably raised, though considerably reduced from preoperative levels. In 14 of those restudied the calculated pulmonary vascular resistance had been over $80 \overrightarrow{\mathcal{E}^{\prime}}$ dyn/s $\mathrm{cm}^{-5}$ before operation. We suggest that if some of these borderline cases serial postoperative recatheterisations are mandatory. Lillehei et al,$^{6}$ in large group, reported only two cases that showe progression of their pulmonary vascular diseasies after closure of a ventricular septal defect. Grosseco Brockhoff and Loogan ${ }^{13}$ reported that all patients is their study who had a normal pressure after closure. of the defect had had a pressure of less than $50 \mathrm{mog}$ $\mathrm{Hg}$ before operation. Our results are at variance. with this. Incomplete surgical closure of the defect has been reported to occur in 4-29\%561415 of casees in different series. We have been gratified thàt residual defects were not evident from oximetry io any of our 69 patients who were recatheterised.

Although uncommon, the combination of paten ductus arteriosus with ventricular septal defeg should be recognised. Hallman et al ${ }^{16}$ found an inc? dence of only $2.6 \%$ in 500 surgically treate $\vec{\delta}$ patients, while in our series there was an incidence of $10 \%$.

The operative mortality in this series was $16.9 \% \%$. Sigman et al $^{4}$ and Allen et al $^{5}$ reported a higher mor tality early in their experience. Hallman et al ${ }^{16}$ i i their study of 500 patients with ventricular septaf defects and pulmonary hypertension noted $26 \%$ early deaths in patients with a systolic pulmonar. artery pressure greater than $80 \%$ of the systemio pressure. From 1976 to 1981 the mortality was only $10 \%$ in our series. Of the 27 subjects with a pup monary vascular resistance of over $800 \mathrm{dyn} / \mathrm{s} \mathrm{cm}-\frac{8}{0}$ there was a $22 \%$ early mortality, which is bette than in other series. ${ }^{5131617}$ The use of cardioplegifo with better intraoperative myocardial preservation and meticulous postoperative care with assisted veno tilation have contributed greatly to these goog results. We have not routinely carried out lung biops sies either before or during operation.

Complete atrioventricular block occurred in on 18 two patients; one died four months after discharge from hospital, while the other is carrying out normos activities, with a heart rate of 60 beats $/ \mathrm{min}, 12$ years after repair. A higher incidence of complete atrioventricular block has been reported in othef series. ${ }^{45}$ Eight patients (3\%) showed evidence of right bundle-branch block with left anterior hemb block. This should be viewed with concern and sucien 
patients need to be followed up carefully. Castaneda $^{18}$ reported a $14 \%$ incidence of this conduction disturbance in his series.

Tricuspid incompetence was not seen in this study after repair. Sigman et al $^{4}$ noted tricuspid incompetence in three subjects after operation, one of whom required repair at the time of reoperation for closure of a residual ventricular septal defect.

Follow-up in 181 long-term survivors for one to 16 years has shown that clinical benefit parallels haemodynamic improvement and all surviving patients are leading normal, active lives. There is still much to be learned, however, about the precise management of the borderline patient and the degree of regression possible in the pulmonary vascular disease in various age groups.

We acknowledge gratefully the help of Dr NK Kejriwal in the compilation of the data and $\mathrm{Mr} \mathrm{V}$ Nagarajan for secretarial assistance.

\section{References}

${ }^{1}$ Roger H. Quoted by Abbott ME.'

${ }^{2}$ Abbott ME. Congenital heart disease. In: Nelson's Loose-leaf medicine 4. New York: Thomas Nelson and Sons, 1932:207.

${ }^{3}$ Lillehei CW, Cohen M, Warden HE, Varco RL. The results of direct vision closure of ventricular septal defect in eight patients by means of controlled cross circulation. Surg Gynec Obstet 1955;101:446-66.

${ }^{4}$ Sigman JM, Perry BL, Behrendt DM, Stern AM, Kirsh MA, Sloan ME. Ventricular septal defect. Results after repair in infancy. Am J Cardiol 1977;39:66-71.

5 Allen HD, Anderson RG, Noren GP, Moller JH. Postoperative follow-up of patients with ventricular septal defect. Circulation 1974;50:465-71.

- Lillehei CW, Anderson RG, Yang Wang. Clinical and hemodynamic changes after closure of ventricular septal defects. JAMA 1968;205:822-7.

' Castaneda A, Zamora R, Nicoloff DM, Moller JH, Hunt CE, Lucas RV. High pressure high resistance ventricular septal defect. Surgical results of closure through right atrium. Ann Thorac Surg 1971;12:29-36.

' Becu LM, Fontana RS, Du Shane JW, Kirklin JW, Burchell HS, Edwards JE. Anatomic and pathologic studies in ventricular septal defect. Circulation 1956;14:349-64.

' Bhati BS, Nandakumar CP, Shatapathy P, John S, Cherian G. Closure of patent ductus arteriosus during open heart surgery. Surgical experience with different techniques.J Thorac Cardiovasc Surg 1972;63:820-6.

${ }^{10}$ Nadas A, Blount GS. Management of ventricular septal defect in adults. Chest 1978;74:3-6.

"Hallidie Smith KA, Wilson RSE, Hart A, Zaidfard E. Functional status of patients with large ventricular septal defect and pulmonary vascular disease 6 to 16 years after surgical closure of the defect in childhood. Br Heart J 1977;39:1093-101.

${ }^{12}$ Freidli B, Langford Kidd BS, Mustard WT, Kieth JD. Ventricular septal defect with increased pulmonary vascular resistance. Late results of surgical closure. Am J Cardiol 1974;33:403-9.

${ }^{13}$ Grosse-Brockhoff F, Loogan F. Ventricular septal defect. Circulation 1968; suppl 37 and 38: 13-20.

${ }^{14}$ Cartmill TB, DuShane JW, McGoon DC, Kirklin JW. Results of repair of ventricular septal defect. J Thorac Cardiovasc Surg 1966;52:486-9.

${ }^{15}$ Hallidie-Smith KA, Hollman A, Cleland WP, Bentall $\mathrm{HH}$, Goodwin JF. Effects of surgical closure of ventricular septal defects upon pulmonary vascular disease. Br Heart J 1969;31:246-60.

${ }^{16}$ Hallman GL, Cooley DA, Wolfe RR, McNamara DG. Surgical treatment of ventricular septal defect associated with pulmonary hypertension. J Thorac Cardiovasc Surg 1964;48:588-600.

${ }^{17}$ Kirklin JW, McGoon DC, DuShane JW. Surgical treatment of ventricular septal defect. J Thorac Surg 1960;40:763-75.

${ }^{18}$ Castaneda A. Modern technics in surgery. In: Cohn LH, ed. Cardiac/thoracic surgery. New York: Futura Publishing Co, 1-10. 